\title{
Identification of supportive care needs in a sample of Puerto Rican cancer patients with the supportive care needs survey
}

\author{
Velda J. González ${ }^{* 1,2}$, Maribel Tirado ${ }^{3}$, Daniel C. Hughes ${ }^{4}$, Elsa Pedro ${ }^{3}$, Michael Velez $^{5}$ \\ ${ }^{1}$ College of Nursing, University of South Florida, Tampa, United States \\ ${ }^{2}$ School of Nursing, University of Puerto Rico, San Juan, Puerto Rico \\ ${ }^{3}$ Comprehensive Cancer Center, University of Puerto Rico, San Juan, Puerto Rico \\ ${ }^{4}$ Health Science Center San Antonio, University of Texas, Texas, United States \\ ${ }^{5}$ Universidad Central del Caribe, Research and Assessment Office, Bayamon, United States
}

Received: February 27, 2015

DOI: $10.5430 /$ jnep.v5n9p32
Accepted: April 14, 2015

Online Published: June 15, 2015

\begin{abstract}
Background: Puerto Ricans are among the largest Hispanic groups in the US. Clinicians/researchers must become skilled in assessing the prevalence of the perceived unmet needs of Puerto Rican cancer patients undergoing treatment to properly respond to their needs, and is an important part of any culturally comprehensive oncological care. Objective: To assess Puerto Rican cancer survivors reports of perceived unmet needs across 5 domains of the cancer experience: "psychological", "health system and information", "physical and daily living", "patient care and support", and "sexuality" and to examine how the perceived unmet needs and disease characteristics are inter-related.

Methods: A cross-sectional survey was conducted from 103 patients (64.1\% female, male $35.9 \%$, mean age 54 years) undergoing cancer treatments. The study participants were $>20$ years of age with breast $(28 \%)$, gynecologic $(21 \%)$, prostate $(17 \%)$ and gastrointestinal (14\%) cancer, mostly on chemotherapy. Overall internal consistency of the Supportive Care Needs Survey was 0.882 .

Results: Patients perceived needs were highest in the domains of sexuality (67\%), physical and daily living (55.3\%), and psychological (38.8\%). Breast cancer was significantly related to reporting unmet needs in the domains of health services/information $(p=.018)$ and sexuality $(p=.009)$. Prostate cancer showed a significant relationship with unmet needs in the domains of psychological $(p=.050)$ and, the physical/daily living $(p<.001)$. Receiving chemotherapy was related with unmet needs in the domains of sexuality $(p=.02)$, and the physical/daily living $(p=.047)$; and, receiving combination of radiation and hormonal therapy was related to unmet needs in the physical/daily living needs domain $(p=.024)$.

Conclusions: The accurate assessment of supportive care needs is important in the management of cancer patients. The unmet supportive care needs of our sample of Puerto Rican cancer patients seem to be affected by cancer site and treatment modality.
\end{abstract}

Key Words: Perceived unmet needs, Supportive care needs, Puerto Rican cancer patients, Cancer treatments

\section{INTRODUCTION}

Advances in early diagnosis and treatment are contributing to an increasing number of people surviving cancer. Cancer in Puerto Rico touches almost every family. According to the Puerto Rico Central Cancer Registry estimate, there are approximately 54,000 cancer survivors in Puerto Rico repre-

\footnotetext{
*Correspondence: Velda J. González; Email: velda.gonzalez@ upr.edu; Address: School of Nursing, University of Puerto Rico Medical Science Campus, PO Box 365067, San Juan, Puerto Rico.
} 
senting approximately $1.4 \%$ of the population. ${ }^{[1]}$ Cancer is the second leading cause of death among Puerto Ricans. ${ }^{[1]}$ On occasions they are diagnosed at a later stage. ${ }^{[2]}$ This may results in a need for more intense treatments, and in experiencing worse symptoms and poorer quality of life (QOL). The intensive, multi-modality treatments of chemotherapy drugs, radiation and surgery that have improved cancer survival often produce disruptive side effects that unexpectedly interfere with the patient's physical and mental functioning affecting their everyday QOL. ${ }^{[3-5]}$ Often these disruptions may manifest themselves as perceived unmet needs that affect not only the individual's QOL but can also affect compliance to treatment regimens and thus impact individual long-term prognosis. As Puerto Ricans are one of the largest Hispanics groups in the US, ${ }^{[6,7]}$ it is crucial that clinicians and researchers become skilled in assessing the prevalence of the perceived unmet needs of Puerto Rican cancer patients undergoing treatment to properly respond to their needs.

Puts, Papoutsis, Springall \& Tourangeau ${ }^{[8]}$ defines unmet needs as "needs that are not addressed and where additional support is required (p.1378)." These unmet needs could be related to cancer and its treatments. The New South Wales (NSW) Cancer Council Supportive Care Review Group and the Cancer Education Research Program ${ }^{[9]}$ encouraged investigators and clinicians to assess the needs of cancer patients within the following dimensions: (a) psychological (needs related to emotions and coping); (b) physical and daily living (needs related to coping with physical symptoms and side effects of treatment and performing usual physical tasks and activities); (c) health system and information (needs related to the treatment center and obtaining information about the disease, diagnosis, treatment, and follow-up); (d) patient care and support (needs related to health care providers showing sensitivity to physical and emotional needs, privacy, and choice); and (e) sexuality (needs related to sexual relationships).

A systematic review provided evidence that up to $93 \%$ of newly-diagnosed patients undergoing cancer treatment complained of unmet needs. ${ }^{[8]}$ Needs from the psychological, information, and in the physical domains were the most commonly reported unmet needs across the studies reviewed by Puts, Papoutsis, Springall \& Tourangeau. ${ }^{[8]}$ Specifically, during cancer treatments, psychological needs, supportive care needs and information needs have been found to be associated with lower resilience, ${ }^{[10]}$ and with fear of cancer recurrence. ${ }^{[11]}$ Others have identified that treatment-related symptoms (i.e., impaired body image, physical and social impairment and gastrointestinal symptoms) significantly predicted the supportive care needs of breast cancer survivors during treatments. ${ }^{[12]}$ In addition, psychological, physical

Published by Sciedu Press and daily living, health system and information, and patient care and support have been found to be associated with symptom distress among Chinese women with advanced breast cancer. ${ }^{[13]}$

Culture influences everyday social life as well as how people and their family and significant others respond to cancer diagnoses and treatment. ${ }^{[14]}$ For example, family members have become aware that satisfying social needs through psychosocial support during cancer treatments might not only impact the course and success of treatment, but also may be beneficial in ameliorating the short and long-term side effects, such as fatigue. ${ }^{[15,16]}$ It has been proposed that meeting patients' needs during cancer treatments helps patients in coping with the disease and is an important part of any comprehensive oncological care. ${ }^{[15]}$ Nonetheless, limited attention has been given to the supportive care needs of Puerto Rican cancer patients during treatments, even though the treatment phase of cancer is frequently perceived by Puerto Ricans as the most difficult and painful one. ${ }^{[16]}$ Needs assessment directly identifies specific issues of need for patients, as well as the perceived magnitude of those needs. ${ }^{[17]}$ If patients' needs are met, adherence to cancer treatments increases, and thus patients' outcomes of QOL and survival thereby improve. Therefore, the purpose of this study was to: (a) assess Puerto Rican cancer survivors reports of perceived unmet needs across 5 domains of the cancer experience: "psychological", "health system and information", "physical and daily living", "patient care and support", and "sexuality"; and (b) to examine how the perceived unmet needs and disease characteristics are inter-related.

\section{METHODS}

This study used an exploratory, cross-sectional design. A convenience sample of Puerto Rican oncology patients receiving treatments $(\mathrm{N}=103)$ was drawn from the oncology clinics at an Oncologic Hospital and at a GYN-Oncology clinics in San Juan, Puerto Rico. Participants were included if they: had a diagnosis of cancer; had received at least two or more rounds of therapy; and, were at least 21 years of age. Approval of the Institutional Review Board was obtained at all sites. Data collection was conducted between August-October 2008.

\subsection{Procedure}

After obtaining written informed consent, participants were asked to complete questionnaires including the Spanish version of the Supportive Care Needs Survey, short form (SCNSSF34) and demographics. ${ }^{[9,17]}$ The SCNS contains 34 items measuring cancer patient's unmet needs across five domains: psychological (10 items), health systems/information (11 
items), patient care/support (5 items), physical/daily living (5 items) and sexuality ( 3 items). For each item, patients are asked to indicate their level of need for help over the last month as the result of having cancer. A typical question for the SCNS-34 is: "In the last month what was your level of need for help with: lack of energy/tiredness". It has a 5-point response scale: "no need: not applicable=1"; "no need: satisfied" $=2$; "low need" = 3 ; "moderate need" $=4$ or "high need = 5". The SCNS-SF34 has been rigorously tested for reliability and validity with Spanish cancer survivors. ${ }^{[18,19]}$ Scores of the SCNS-SF34 can range between 0 and 136. ${ }^{[20,21]}$ High scores mean higher level of unmet needs. Cronbach alpha of 0.88 was obtained.

\subsection{Treatment of data}

Descriptive statistics were performed on demographics and disease characteristics of the sample. The prevalence of perceived unmet needs was obtained by calculating the frequency of the options endorsed for each item. Analysis of disease characteristic with respect to each domain was performed and tested for significance by chi-square analysis. Problems identified by survivors were dichotomized as present or absent and $\chi^{2}$ tests were used to evaluate univariate associations with selected characteristics. All data analyses were conducted using Statistics Package for Social Sciences SPSS, version 18.0 for windows. Statistical significance was considered with a $p$-value less than .05 .

\section{RESUlts}

The demographic and disease characteristics of the 103 participants are illustrated in Tables 1 and 2. Participants were mostly female (64\%); age ranged from 21 to 75 years, with a mean age of 54. The majority of the subjects surveyed had achieved some level of college degree $(43.7 \%)$ and lived with a spouse $(55.3 \%)$. As shown on Table 2 the majority of the participants had breast (28\%) or gynecologic cancer (21\%), with the most frequent cancer treatment been chemotherapy (83\%). In addition, fifty two percent of the subjects had a recent cancer diagnosis, (i.e., less than 10 months from the interview date).

Overall, participants' reported having moderate to high needs for help (>30\%) in four of the five domains; sexuality (67\%), physical/daily living (55\%), psychological (39\%), and health system/information need (31\%). As shown in Table 3, from the ten items with the highest frequency of reported moderate to high needs for help, five items were from the physical/daily living domain, three items from the health system/information domain, and two items from the psychological domain. The top five individual items with the highest frequencies of moderate to high need reported were: "con- cern about the worries of those close to you" (67\%), "lack of energy/tiredness" (50\%), "not been able to do things you used to do" (39\%), "being informed about things you can do to help yourself to get well" (39\%), and "feeling unwell a lot of the time" $(38 \%)$.

Table 1. Demographic characteristics of study participants

\begin{tabular}{ll}
\hline Characteristics & N (\%) \\
\hline Age & $11(10.7)$ \\
$21-39$ & $22(21.4)$ \\
$40-49$ & $18(17.5)$ \\
$50-59$ & $29(28.2)$ \\
$60-69$ & $23(22.3)$ \\
$70+$ & \\
Gender & $66(64.1)$ \\
Female & $37(35.9)$ \\
Male & \\
Marital status & $57(55.3)$ \\
Married/Living together & $46(44.7)$ \\
Single & \\
Highest education completed & $27(26.2)$ \\
Elementary/middle school & $31(30.1)$ \\
High School & $45(43.7)$ \\
College & \\
Health Insurance* & $38(36.9)$ \\
Primary or secondary health reform & $64(62.1)$ \\
Other & \\
\hline *Health Insurance information was missing for one patient
\end{tabular}

*Health Insurance information was missing for one patient

Table 2. Participants' diseases characteristics

\begin{tabular}{ll}
\hline Characteristics & N (\%) \\
\hline Cancer Site & $29(28.2)$ \\
Breast & $22(21.4)$ \\
Gynecological & $17(16.5)$ \\
Prostate & $14(13.6)$ \\
Gastro-intestinal & $6(5.8)$ \\
Head \& Neck & $15(14.5)$ \\
Others & \\
Cancer Treatment & $66(64.1)$ \\
Chemotherapy & $37(35.9)$ \\
Radiotherapy & $14(13.6)$ \\
Chemotherapy \& Radiotherapy & $9(8.7)$ \\
Surgery & $7(6.8)$ \\
Hormone \& Radiotherapy & $3(2.9)$ \\
Other Combination & \\
Year of Cancer Diagnosis & $53(51.5)$ \\
$>2007$ & $44(42.7)$ \\
2002-2007 & $6(5.8)$ \\
$<2002$ &
\end{tabular}


Furthermore, cancer site and cancer treatment modality were psychological $(p=.050)$ and, the physical/daily living $(p<$ significantly related to unmet needs as shown in Table 4. .001). Other significant relationships showed that receiving Breast cancer was significantly related to reporting unmet chemotherapy was related with unmet needs in the domains needs in the domains of health services/information $(p=$ $.018)$ and sexuality $(p=.009)$. Similarly, gastrointestinal cancer was related with reporting unmet needs for health services/information $(p=.037)$. Prostate cancer showed a significant relationship with unmet needs in the domains of of sexuality $(p=.02)$, and the physical/daily living $(p=.047)$; and, receiving combination of radiation and hormonal therapy was related to unmet needs in the physical/daily living needs domain $(p=.024)$. Recent surgery, was also related to having unmet needs in the sexuality domain $(p<.001)$.

Table 3. Top 10 unmet needs endorsed

\begin{tabular}{llll}
\hline Domain & Item & $(\%)$ & $(67.0)$ \\
\hline Psychological & Concern about the worries of those close to you & (49.5) \\
Physical \& daily living & Lack of energy/tiredness & (38.8) \\
Physical \& daily living & Not being able to do the things you used to do & (37.7) \\
Health system \& information & Being informed about the things you can do to help yourself get well. & (37.9) \\
Physical \& daily living & Feeling unwell a lot of the time & (34.0) \\
Psychological & Feeling down or depressed & (34.0) \\
Health system \& information & Being given written information about the important aspects of your care & (34.0) \\
Health system \& information & Being given information about managing your illness and side effects at home & (33.0) \\
Physical \& daily living & Work around the home & Pain & (32.0) \\
\hline
\end{tabular}

Note. ${ }^{*}=\%$ of those who endorsed item as moderate/high need

Table 4. Predictors of endorsement of unmet needs by cancer site and treatment modality

\begin{tabular}{|c|c|c|c|c|c|c|c|c|c|c|c|c|c|c|c|}
\hline \multirow[t]{2}{*}{ Characteristic (n) } & \multicolumn{3}{|c|}{ Psychological } & \multicolumn{3}{|c|}{$\begin{array}{l}\text { Health System \& } \\
\text { Information }\end{array}$} & \multicolumn{3}{|c|}{$\begin{array}{l}\text { Physical \& Daily } \\
\text { Living }\end{array}$} & \multicolumn{3}{|c|}{$\begin{array}{l}\text { Patient Care \& } \\
\text { Support }\end{array}$} & \multicolumn{3}{|c|}{ Sexuality } \\
\hline & $\mathbf{N}$ & $(\%)$ & $P$ & $\mathbf{n}$ & $(\%)$ & $P$ & $\mathbf{n}$ & $(\%)$ & $P$ & n & $(\%)$ & $p$ & $\mathbf{n}$ & $(\%)$ & $p$ \\
\hline \multicolumn{16}{|l|}{ Cancer Site } \\
\hline \multicolumn{16}{|l|}{ Breast } \\
\hline Yes (29) & 12 & (41.4) & \multirow{2}{*}{.740} & 14 & $(48.3)$ & \multirow{2}{*}{$.018^{*}$} & 20 & $(69.0)$ & \multirow{2}{*}{.082} & 5 & $(17.2)$ & \multirow{2}{*}{.177} & 25 & & \multirow{2}{*}{$.009 * *$} \\
\hline No (74) & 28 & (37.8) & & 18 & (24.3) & & 37 & $(50.0)$ & & 6 & $(8.1)$ & & 44 & (59.5) & \\
\hline \multicolumn{16}{|l|}{ Gastrointestinal } \\
\hline Yes (14) & 4 & (28.6) & \multirow{2}{*}{.397} & 1 & $(7.1)$ & \multirow{2}{*}{$.037 *$} & 8 & (57.1) & \multirow{2}{*}{.884} & 2 & (14.3) & \multirow{2}{*}{.638} & 10 & (71.4) & \multirow{2}{*}{.704} \\
\hline No (84) & 36 & $(40.4)$ & & 31 & $(34.8)$ & & 49 & (55.1) & & 9 & $(10.1)$ & & 59 & (66.3) & \\
\hline \multicolumn{16}{|l|}{ Prostate } \\
\hline Yes (17) & 3 & $(17.6)$ & \multirow{2}{*}{$.050 *$} & 5 & (29.4) & \multirow{2}{*}{.872} & 2 & (11.8) & \multirow{2}{*}{$.001 * *$} & 0 & $(0.0)$ & \multirow{2}{*}{.119} & 9 & (52.9) & \multirow{2}{*}{.178} \\
\hline No (86) & 37 & $(43.0)$ & & 27 & (31.4) & & 55 & $(64.0)$ & & 11 & $(12.8)$ & & 60 & (69.8) & \\
\hline \multicolumn{16}{|l|}{ Cancer } \\
\hline \multicolumn{16}{|l|}{ Treatment } \\
\hline \multicolumn{16}{|l|}{ Chemotherapy } \\
\hline Yes (47) & 22 & $(46.8)$ & \multirow{2}{*}{.128} & 12 & $(25.5)$ & \multirow{2}{*}{.266} & 31 & $(66.0)$ & $.047 *$ & 6 & (12.8) & .530 & 37 & $(78.7)$ & $.020 *$ \\
\hline No (56) & 18 & (32.1) & & 20 & (35.7) & & 26 & $(46.4)$ & & 5 & (8.9) & & 32 & $(57.1)$ & \\
\hline $\begin{array}{l}\text { Radiation \& } \\
\text { Hormonal }\end{array}$ & & & & & & & & & & & & & & & \\
\hline Yes (7) & 1 & (14.3) & .167 & 4 & (57.1) & .123 & 1 & (14.3) & $.024 *$ & 0 & $(0.0)$ & .343 & 4 & 57.1 & .566 \\
\hline No (96) & 39 & (40.6) & & 28 & (29.2) & & 56 & (58.3) & & 11 & (11.5) & & 65 & (67.7) & \\
\hline Surgery & & & & & & & & & & & & & & & \\
\hline Yes (9) & 2 & (22.2) & .284 & 4 & (44.4) & 364 & 3 & (33.3) & 164 & 0 & $(0.0)$ & 278 & 1 & (11.1) & $001 * *$ \\
\hline No (94) & 38 & $(40.4)$ & & 28 & (29.8) & & 54 & (57.4) & & 11 & (11.7) & & 68 & (72.3) & \\
\hline
\end{tabular}




\section{Discussion}

The primary aim of our study was to assess perceived unmet needs on the specific ethnic cancer survivor population of 103 Puerto Rican cancer survivors across 5 domains of the cancer experience: "psychological", "health system and information", "physical and daily living", "patient care and support", and "sexuality". The majority of participants reported having unmet needs in the "psychological", "physical activity/daily living", and the "sexual" domains. These findings are similar to that found by Im et al. ${ }^{[18]}$ in which Hispanics tended to report the highest scores in most categories of needs compared with Asians, African Americans, and Whites. These results may suggest the need for the health system in PR and health care professionals to shift their efforts, not only to be able to improve patient care services, but also, to assess and develop interventions to meet the physical, psychological, and sexuality needs of this population. In addition, there is a need to recognize that regardless of patients' cancer diagnoses or type of treatment, underassessment of needs, can contribute to patients' development of physical limitations and psychological impairments; also, to an increased risk for non-adherence to cancer treatments that compromises the QOL of cancer survivors.

Interestingly, the highest reported need was from the psychological domain, "concern about the worries of those close to you". This finding is congruent with a study of Carelle and colleagues, ${ }^{[22]}$ in which cancer patients rated the psychosocial complaint of "affects my family or partner" as the most severe chemotherapy side effect. The implementation of support groups for patients and their family at the above mentioned clinics with the integration of the concepts of faith, positive thinking, and humor (Hispanic cultural ways of coping with cancer) deserves consideration. Also within the top ten were three items from the "health system and information" domain. The fourth item endorsed is the typical expected response from this domain: "being informed about the things you can do to help yourself get well". These results suggest that aspects of their care and on how they can manage illness and side effects at home should be a constant priority in the education offered by the health care team while patients are on active treatment.

As expected, given that our participants were receiving cancer treatments, six out of the top ten individual items reported were in the "physical and daily living" domain, consistent with symptoms of side effects of treatment (e.g., "lack of energy/tiredness"). Special attention should be given to the assessment of symptoms during cancer treatments as not only symptoms represents a problem for patients; it also places a significant burden on the health care system. For example, the symptom of fatigue has been found associated with a 75\% alteration in employment status, increased hospitalizations, negatively affect patient's compliance with treatment, need of dose limiting or interruption of treatments, and predictor of poor survival. ${ }^{[23-25]}$ In addition, the high frequency of reported un-meet need of "being informed about the things you can do to help yourself get well" suggest that self-care alleviation practices should be a constant priority in the education of patients receiving cancer treatments.

Even though participants reported a highest prevalence of having needs in the sexuality domain, no individual needs in this domain were reported as the top ten. However, this finding is consistent with the Carelle and colleagues ${ }^{\left[{ }^{[22]}\right.}$ study in which subjects on chemotherapy rated sexual concerns among their top issues to deal with. Surprisingly, "fears about cancer spreading and cancer returning" did not show among the ten highest needs like has been shown in other similar studies. ${ }^{[26-28]}$ This result may be related to the fact that majority of our participants were recently diagnosed and that they may not think about recurrence so close to their initial diagnosis.

With respect to the objective of examining how the perceived unmet needs and disease characteristics are inter-related it was found that almost all of the disease characteristics were identified as a significantly related to at least one domain (i.e., breast cancer diagnosis was related to the "health services/information" and to the "sexuality"). Interestingly, the domain of patient care \& support was the only variable that did not showed a significant relationship to any of the disease characteristics. This result suggest that regardless the participants diagnoses or type of treatment, the health care providers of the participants of this study might have showed sensitivity to their physical and emotional needs, privacy, and choice during the cancer experience. However, prostate cancer participants as well as participants receiving chemotherapy, and radiotherapy combined with hormonal treatment were significantly more likely to report "physical and daily living" needs. These results suggest that prostate cancer survivors as well as those survivors during treatments should receive constant assessment and information on aspects of managing illness, benefits and side effects of treatments. Similarly, those with recent surgery and/or chemotherapy were more likely to report needs in the sexuality domain. This finding is consistent with the Carelle and colleagues ${ }^{\text {'22] }}$ study in which subjects on chemotherapy rated sexual concerns among their top issues to deal with suggesting that cancer survivors should receive priority information on aspects of managing intimate relationships during cancer treatments. In summary, our findings suggest that there are specific unmet needs that warrant attention from health care providers. 


\section{Limitations}

As a limitation, participants frequently cited the concepts of "optimism", "being sane", "faith", and "God" as self-care strategies to cope with in their needs; however, these variables were not measured. In addition, the study could have benefited from using the longer SCNS form that includes additional items on needs for financial and transportation assistance; unmet needs frequently mentioned by our participants. Generalizability of this finding is limited to the sample that participated in the study. Future research is warranted for expanding this study to larger sample populations. One area that warrants attention will be comparing the perceived needs of survivors actively receiving treatment to those who are post treatment. Other studies could be made to compare needs of island Puerto Rican cancer survivors and mainland Puerto Ricans.

\section{Conclusion}

Assessing the unmet needs in Puerto Rican cancer patients, the magnitude of those unmet needs and its relationship with disease characteristics are an integral part of a culturally comprehensive oncology care. Further, these study findings should provide nurses and other clinicians with information to educate and empower our Puerto Rican patients undergoing treatment to notify their supportive care needs so we can develop an optimal plan to properly respond to their needs. Well informed oncology patients have better treatment outcomes, adherence to treatments, and have enhanced QOL following treatment.

\section{ACKNOWLEDGements}

Special appreciation to Dr. Josefina Romagueras, Dr. Sharee Ann Umpierre, Maria del Pilar Cotto, RN, Mayra Colon, RN, University of Puerto Rico, School of Medicine, Department of Gynecology; Dr. Reynold Lopez, Dr. Alberto Cardona, and Dr. Edna Mora, University of Puerto Rico, School of Medicine, Department of Surgery; Dr. Carlos Chevere-Mourino, Dr. Luis Delgado-Mateu, and the Nursing Staff of the Oncologic Hospital Dr. Isaac Gonzalez Martinez for facilitating data collection process. Dr. Hector L. Banchs-Pieretti, University of Puerto Rico, School of Medicine, Department of Medicine, for consultation and assisting in content analysis.

\section{CONFLICTS OF INTEREST Disclosure}

The authors declare that they have no competing interests.

\section{REFERENCES}

[1] Puerto Rico Health Department. Puerto Rico Chronic Disease Action Plan 2014-2020 [Internet]. Chronic Disease Prevention and Control Division Secretariat for Health. Puerto Rico; [cited 2014 Jul 9]. Available from: http://www.salud.gov.pr/RCancer/Documen ts/Cancer\%20in\%20Puerto\%20Rico\%202004.pdf

[2] Puerto Rico Cancer Control Coalition, Puerto Rico ComprehensiveCancer Control Plan 2008-2013, (2008). Unpublished Manuscript

[3] Eversley R, Estrin D, Dibble S, et al. Post-treatment symptoms among ethnic minority breast cancer survivors. Oncol Nurs Forum. 2005; 32(2): 250-256. http://dx.doi.org/10.1188/05.onf . 250-256

[4] Hickok JT, Roscoe JA, Morrow GR, et al. Frequency, severity, clinical course, and correlates of fatigue in 372 patients during 5 weeks of radiotherapy for cancer. Cancer. 2005; 104(8): 1772-1778. PMid:16116608 http://dx.doi.org/10.1002/cncr. 21364

[5] Monga U, Kerrigan AJ, Thornby J, et al. Longitudinal study of quality of life in patients with localized prostate cancer undergoing radiotherapy. J Rehabil Res Dev. 2005; 42(3): 391-399. http://dx.doi.org/10.1682/JRRD.2004.06.0071

[6] US. Department of Commerce, US census Bureau, Population Division. Puerto Rico and the Island Areas. 2010. Available from: http://www. census.gov/prod/2011pubs/12statab/ outlying.pdf

[7] Collazo S, Ryan C, Bauman K. Profile of the Puerto Rican Population in United States and Puerto Rico: 2008. Available from: http://www.census.gov/hhes/socdemo/education/data /acs/paa2010/Collazo_Ryan_Bauman_PAA2010_Paper.pdf

Published by Sciedu Press
[8] Puts MT, Papoutsis A, Springall E, et al. A systematic review of unmet needs of newly diagnosed older cancer patients undergoing active cancer treatment. Support Care Cancer. 2012; 20(7): 1377-1394 PMid:22476399 http://dx.doi.org/10.1007/s00520-012-1 450-7

[9] Sanson-Fisher R, Girgis A, Boyes A, et al. The unmet supportive care needs of patients with cancer. Supportive Care Review Group. Cancer 2000; 88(1): 226-237. http://dx.doi.org/10.1002/(SICI) 1 097-0142 (20000101) 88: 1<226: : AID-CNCR30>3 . 0 . CO;2-P

[10] Dubey C, De Maria J, Hoeppli C, et al. Resilience and unmet supportive care needs in patients with cancer during early treatment: A descriptive study. Eur J Oncol Nurs. 2015. PMid:25882547 http://dx.doi.org/10.1016/j.ejon.2015.03.004

[11] Sarkar S, Sautier L, Schilling G, et al. Anxiety and fear of cancer recurrence and its association with supportive care needs and healthcare service utilization in cancer patients. J Cancer Surviv. 2015 PMid:25676473 http://dx.doi.org/10.1007/s11764-015-0 434-2

[12] Schmid-Buchi S, Halfens RJ, Muller M, et al. Factors associated with supportive care needs of patients under treatment for breast cancer. Eur J Oncol Nurs. 2013; 17(1): 22-29. PMid:22449715 http://dx.doi.org/10.1016/j.ejon.2012.02.003

[13] Au A, Lam W, Tsang J, et al. Supportive care needs in Hong Kong Chinese women confronting advanced breast cancer. Psychooncology. 2013; 22(5): 1144-1151. PMid:22715115 http://dx.doi.o $\mathrm{rg} / 10.1002 /$ pon. 3119

[14] Brix C, Schleussner C, Fuller J, et al. The need for psychosocial support and its determinants in a sample of patients undergoing radiooncological treatment of cancer. J Psychosom Res. 2008; 65(6): 
541-548. PMid:19027442 http://dx.doi.org/10.1016/j.jps ychores. 2008.05.010

[15] So WK, Leung DY, Ho SS, et al. Associations between social support, prevalent symptoms and health-related quality of life in Chinese women undergoing treatment for breast cancer: a cross-sectional study using structural equation modelling. Eur J Oncol Nurs. 2013; 17(4): 442-448. PMid:23238353 http://dx.doi.org/10.1016 /j.ejon.2012.11.001

[16] Berrios-Rivera R, Rivero-Vergne A, Romero I. The pediatric cancer hospitalization experience: reality co-constructed. J Pediatr Oncol Nurs. 2008; 25(6): 340-353. PMid:18812589 http://dx.doi.org /10.1177/1043454208323618

[17] Bonevski B, Sanson-Fisher R, Girgis A, et al. Evaluation of an instrument to assess the needs of patients with cancer. Supportive Care Review Group. Cancer. 2000; 88(1): 217 225. http://dx.doi.org/10.1002/(SICI) 1097-0142(2000 0101) $88: 1<217::$ AID-CNCR29>3.0.CO;2-Y

[18] Im EO, Chee W, Guevara E, et al. Gender and ethnic differences in cancer patients' needs for help: an Internet survey. Int J Nurs Stud. 2008; 45(8): 1192-1204. PMid:17963769 http://dx.doi .org/1 $0.1016 / j . i j n u r s t u .2007 .09 .006$

[19] Doubova SV, Aguirre-Hernandez R, Gutierrez-de la Barrera M, et al. Supportive care needs of Mexican adult cancer patients: validation of the Mexican version of the Short-Form Supportive Care Needs Questionnaire (SCNS-SFM). Support Care Cancer. 2015.

[20] Boyes A, Zucca A, Lecathelinais C, et al. Supportive Care Needs Survey: Supplement 1A: Long-term cancer survivors reference data Center for Health Research and Psycho-oncology; Newcastle: 2006.

[21] McElduff P, Boyes A, Zucca A, et al. The Supportive Care Needs Survey: A guide to administration, scoring and analysis. Centre for
Health Research \& Psycho-Oncology [Internet]. 2004: [cited 2014 Jul 5]. Available from: http://www.researchgate.net

[22] Carelle N, Piotto E, Bellanger A, et al. Changing patient perceptions of the side effects of cancer chemotherapy. Cancer. 2002; 95(1): 155163. PMid:12115329 http://dx.doi.org/10.1002/cncr. 1063 0

[23] Curt GA, Breitbart W, Cella D, et al. Impact of cancer-related fatigue on the lives of patients: new findings from the Fatigue Coalition. Oncologist. 2000; 5(5): 353-360. http://dx.doi.org/10.1634 /theoncologist.5-5-353

[24] Franklin DJ, Packel L. Cancer-related fatigue. Arch Phys Med Rehabil. 2006; 87(3 Suppl 1): S91-93.

[25] Jereczek-Fossa BA, Marsiglia HR, Orecchia R. Radiotherapyrelated fatigue. Crit Rev Oncol Hematol. 2002; 41(3): 317-325. http://dx.doi.org/10.1016/S1040-8428(01)00143-3

[26] Hwang SY, Park BW. The perceived care needs of breast cancer patients in Korea. Yonsei Med J. 2006; 47(4): 524-533. PMid:16941743 http://dx.doi.org/10.3349/ymj.2006.47.4.524

[27] Macvean ML, White VM, Pratt S, et al. Reducing the unmet needs of patients with colorectal cancer: a feasibility study of The Pathfinder Volunteer Program. Support Care Cancer. 2007; 15(3): 293-299. PMid:16947039 http://dx.doi.org/10.1007/s00520-006-0 128-4

[28] Mulders M, Vingerhoets A, Breed W. The impact of cancer and chemotherapy: perceptual similarities and differences between cancer patients, nurses and physicians. Eur J Oncol Nurs. 2008; 12(2): 97-102. PMid:18242139 http://dx.doi.org/10.1016/j.ejon. 2007.10 .002 